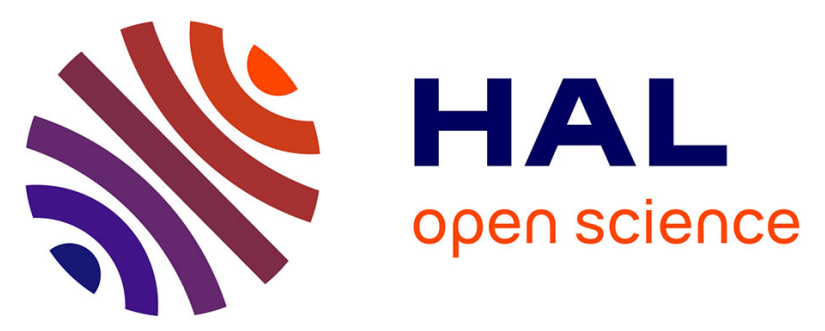

\title{
Free DNA precipitates calcium phosphate apatite crystals in the arterial wall in vivo
}

Raphaël Coscas, Marie Bensussan, Marie-Paule Jacob, Liliane Louedec, Ziad

Massy, Jérémy Sadoine, Michel Daudon, Catherine Chaussain, Dominique

Bazin, Jean-Baptiste Michel

\section{To cite this version:}

Raphaël Coscas, Marie Bensussan, Marie-Paule Jacob, Liliane Louedec, Ziad Massy, et al.. Free DNA precipitates calcium phosphate apatite crystals in the arterial wall in vivo. Atherosclerosis, 2017, 259, pp.60 - 67. 10.1016/j.atherosclerosis.2017.03.005 . hal-01489287

\section{HAL Id: hal-01489287 \\ https://hal.sorbonne-universite.fr/hal-01489287}

Submitted on 14 Mar 2017

HAL is a multi-disciplinary open access archive for the deposit and dissemination of scientific research documents, whether they are published or not. The documents may come from teaching and research institutions in France or abroad, or from public or private research centers.
L'archive ouverte pluridisciplinaire HAL, est destinée au dépôt et à la diffusion de documents scientifiques de niveau recherche, publiés ou non, émanant des établissements d'enseignement et de recherche français ou étrangers, des laboratoires publics ou privés. 
Free DNA precipitates calcium phosphate apatite crystals in the arterial wall in vivo

Raphaël Coscas ${ }^{1,2,3^{*}}$, Marie Bensussan ${ }^{1,4}$, Marie-Paule Jacob ${ }^{1}$, Liliane Louedec ${ }^{1}$, Ziad Massy ${ }^{3}$, Jeremy Sadoine ${ }^{5}$, Michel Daudon ${ }^{6}$, Catherine Chaussain ${ }^{5}$, Dominique Bazin ${ }^{7}$, Jean-Baptiste Michel $^{1}$

${ }^{1}$ UMR 1148, Inserm-Paris7 - Denis Diderot University, Xavier Bichat Hospital, 75018 Paris, France.

${ }^{2}$ UMR 1173, Inserm-Paris11 - Faculty of Health Sciences Simone Veil, Versailles SaintQuentin-en-Yvelines University, Paris-Saclay University, 78180 Montigny-le-Bretonneux; and Department of Vascular Surgery, Ambroise Paré University Hospital, AP-HP, 92104 Boulogne-Billancourt, France.

${ }^{3}$ UMR 1018, Inserm-Paris11 - CESP, Versailles Saint-Quentin-en-Yvelines University, ParisSaclay University, Paul Brousse Hospital, 94807 Villejuif; and Department of Nephrology, Ambroise Paré University Hospital, AP-HP, 92104 Boulogne-Billancourt, France.

${ }^{4}$ Jules Verne University of Picardie and Department of Vascular Surgery, Amiens-Picardie University Hospital, 80054 Amiens, France

${ }^{5}$ Laboratoire EA2496 et Plateforme d'Imagerie du Vivant (PIV), Paris Descartes University, Sorbonne Paris Cité, Montrouge, France.

${ }^{6}$ Service d'Explorations Fonctionnelles Multidisciplinaires, AP-HP, Hôpital Tenon, Paris, France, Inserm, UMR S 1155, Hôpital Tenon, Paris, France.

${ }^{7}$ CNRS, Laboratoire de Chimie de la Matière Condensée de Paris, UPMC, Collège de France, Paris, France, and Laboratoire de Physique des Solides, Université Paris XI, Orsay, France. 
*Corresponding author: Department of Vascular Surgery, Ambroise Paré University Hospital, AP-HP 9, avenue Charles de Gaulle, 92104 Boulogne-Billancourt, France

E-mail address: rcoscas@gmail.com (R. Coscas)

Keywords: Free DNA, Calcium score, Smooth muscle cell, Calcification, Aneurysm, Human atherosclerosis 
Background and aims: The arterial wall calcium score and circulating free DNA levels are now used in clinical practice as biomarkers of cardiovascular risk. Calcium phosphate apatite retention in the arterial wall necessitates precipitation on an anionic platform. Here, we explore the role of tissue-free DNA as such a platform.

Methods: The first step consisted of histological observation of samples from human and rat calcified arteries. Various stains were used to evaluate colocalization of free DNA with calcified tissue (alizarin red, fluorescent Hoechst, DNA immunostaining and TUNEL assay). Sections were treated by EDTA to reveal calcification background. Secondly, a rat model of vascular calcifications induced by intra-aortic infusions of free DNA and elastase + free DNA was developed. Rat aortas underwent a micro-CT for calcium score calculation at 3 weeks. Rat and human calcifications were qualitatively characterized using $\mu$ Fourier Transform Infrared Spectroscopy ( $\mu$ FTIR) and Field Emission-Scanning Electron Microscopy (FESEM).

Results: Our histological study shows colocalization of calcified arterial plaques with free DNA. In the intra-aortic infusion model, free DNA was able to penetrate into the arterial wall and induce calcifications whereas no microscopic calcification was seen in control aortas. The calcification score in the elastase + free DNA group was significantly higher than in the control groups. Qualitative evaluation with $\mu$ FTIR and FE-SEM demonstrated typical calcium phosphate retention in human and rat arterial specimens.

Conclusions: This translational study demonstrates that free DNA could be involved in arterial calcification formation by precipitating calcium phosphate apatite crystals in the vessel wall. 


\section{INTRODUCTION}

The arterial wall is a frequent target of the abnormal process of soft tissue calcification, associated with numerous vascular pathologies, including atherosclerosis, aging, renal failure, diabetes and rare genetic diseases ${ }^{1}$. Therefore, the arterial wall calcium score quantified by Xray scanning is now used in clinical practice as one of the strongest biomarkers of cardiovascular risk ${ }^{2,3}$. Nevertheless, the pathophysiology of initial calcium phosphate precipitation in the vascular system is probably not unique, and remains not completely understood $^{4}$. This process necessitates changes in the balance between ionized calcium and phosphate concentrations, under the control of smooth muscle cell (SMC) alkaline phosphatase, which hydrolyzes organic phosphorous ${ }^{5}$ as substrate for phosphate release within the arterial tissue. It also necessitates calcium phosphate precipitation on anionic platforms, usually represented by matrix vesicles ${ }^{6}$. Indeed, there are arguments that initial calcium phosphate precipitation ${ }^{7}$ could be, at least in part, associated with cell stress and death, via the release of phosphorous from intracellular metabolism and pro-calcifying membrane phospholipid-rich micro-particles ${ }^{8-10}$. On the other hand, the poly-anionic nature of free DNA causes it to strongly interact with cationic calcium phosphate, and DNA is an important source of phosphates. For example, hydroxyapatite columns were initially used to purify DNA ${ }^{11}$, and calcium phosphate nanoparticles are now used as vectors for cell DNA transfection $^{12}$. Nevertheless, to the best of our knowledge, the role of arterial wall free DNA in the initiation of calcifications has not yet been explored in the microenvironment of atherosclerotic pathologies.

The purpose of this study was to explore the colocalization of free DNA and calcifying nucleation in initial atheroma in human aortic tissue and in intraluminal buds in the late stages of femoral atherosclerosis, to define the nature of these calcified nuclei, and lastly, to develop 
an animal model in which arterial calcifications are induced by intraluminal infusion of fragmented autologous DNA. 


\section{MATERIALS AND METHODS}

This study consists of 2 parts: (1) the histological examination of calcifications from human and rat arteries, (2) the characterization of a rat model of vascular calcifications, induced by intra-aortic infusions of free DNA in various situations.

\section{Histological examination of calcifications from human and rat arteries}

\section{Human arteries}

Samples of apparently healthy human aorta $(n=6)$ from the Inserm U1148 Biobank were analyzed. Aortas that displayed early stages of atheroma (fibrous cap atheroma) were analyzed further. Aortas were obtained from deceased organ donors with the authorization of the French Biomedicine Agency (PFS 09-007) and after submission of a legal statement to the French Ministry of Research. Samples were fixed in 5\% paraformaldehyde, embedded in paraffin and cut into $6 \mu \mathrm{m}$-thick sections for histological analysis. Similarly, samples of stenosed common femoral arteries $(n=6)$, obtained at endarterectomy from our vascular surgery department (Xavier Bichat Hospital, AP-HP, 75018 Paris), were also fixed, embedded in paraffin and cut for histological analysis with or without prior treatment with ethylenediaminetetraacetic acid (EDTA). This EDTA treatment was used because of its ability to chelate calcium phosphate, thereby revealing background hidden by calcium phosphate precipitation.

\section{Rat aneurysmal aortas}

Aortic samples from rats that underwent intraluminal aortic perfusion of pancreatic elastase, along with, or without, repeated injections of Porphyromonas gingivalis (PG) as previously described $^{13}$, were fixed in $5 \%$ paraformaldehyde and embedded in paraffin to obtain $6 \mu \mathrm{m}$ thick sections for histological analysis. 


\section{Histological examination}

Harvested arteries were embedded in paraffin and $6 \mu \mathrm{m}$ sections were cut. Sections were deparaffinized and rehydrated in toluene and ethanol baths. Several stains were used: hematoxylin-eosin or Masson's trichrome to explore the arterial structure, Alizarin red to detect calcifications, Hoechst (binding of DNA Adenine and Thymine), DNA immunostaining (ab27156, Abcam) and TUNEL assay (fragmented DNA, Roche) before and after decalcification by EDTA incubation, for free DNA visualization.

\section{Rat model of vascular calcifications}

\section{Free DNA preparation}

Two Wistar rats were sacrificed under pentobarbital anesthesia $(0.3 \mathrm{cc} / 100 \mathrm{~g})$. Both lungs were harvested and kept at $-20^{\circ} \mathrm{C}$. The QIAamp DNA blood maxi (Qiagen) kit was used with some modifications of the protocol. Forty $\mathrm{mL}$ of ATL Qiagen lysis buffer and $4 \mathrm{~mL}$ of Qiagen proteinase $\mathrm{K}$ were added and incubated with lungs overnight at $+56^{\circ} \mathrm{C}$ to rupture cell membranes. The $46 \mathrm{~mL}$ resulting solution was homogenized and distributed into 4 tubes. In each tube, $11.5 \mathrm{~mL}$ of AL Qiagen buffer and an equal volume of absolute ethanol were added. Following a 15-minute centrifugation at $760 \mathrm{G}$, the supernatant was loaded onto 4 Qiagen columns including a silica membrane to fix free DNA.

After two washings of each column, free DNA was then eluted with $1 \mathrm{~mL}$ of sterile water. Optical densities were measured at 260 and $280 \mathrm{~nm}$ using a NanoDrop spectrophotometer to assess the quality and quantity of the resulting DNA solutions. Aliquots of 300 microL were sonicated for 36 minutes with intermittent cooling periods at $4^{\circ} \mathrm{C}$ each 6 minutes. The ultrasound waves caused the fragmentation of DNA. Fragment sizes were measured by agarose gel electrophoresis with a DNA scale and were comprised between 100 and $600 \mathrm{bp}$. Following fragmentation, DNA was mixed with a Hoechst solution. 


\section{Surgical procedure: in vivo intra-aortic perfusion of free DNA}

Male Wistar rats (7-8 weeks, 300-350 grams) were randomized for intra-aortic infusion of various solutions: free DNA alone, elastase infusion followed by free DNA infusion, elastase alone and isotonic saline alone (control group). The procedure and the animal care complied with the principles formulated by the National Society for Medical Research (animal facility agreement: $n^{\circ}$ B75-18-03, experimentation authorization $\left.n^{\circ} 75-101\right)$, and this study was performed after a favorable decision of the Institutional Review Board for Animal Care, with the declaration $\left(n^{\circ} 5743\right)$ to the French Ministry of Research.

The technique was similar to the aneurysm model of intra-aortic perfusion of pancreatic elastase $^{14}$. Briefly, following general anesthesia with pentobarbital and midline laparotomy, the abdominal aorta was exposed over 15 millimeters. Collaterals were ligated using 9/0 polypropylene sutures. The aorta was clamped below the renal artery and at the level of the bifurcation, this isolating an infra-aortic segment. A distal transversal arteriotomy allowed introduction of a polyethylene microcatheter PE-10 (Clay Adams, Parsippany, NJ) into this segment. The distal aorta was secured to the catheter to avoid leaks and the infrarenal aortic segment was perfused at $0.55 \mathrm{~mL} / \mathrm{h}$ constant flow for 20 minutes. After perfusion, the catheter was retrieved and the aortotomy closed using interrupted sutures of polypropylene $10 / 0$. The midline laparotomy was closed in a standard fashion and an analgesic subcutaneous injection of Buprenorphine $(0.1 \mathrm{mg} / \mathrm{kg})$ was given.

\section{Perfused solutions}

Rats were first perfused with an elastase solution (25\%) or with an isotonic solution $(\mathrm{NaCl}$ 9\%o, control animals) during 5 minutes. Then, animals were perfused with the fragmented DNA $(0.25 \mu \mathrm{g} / \mu \mathrm{L})$ or with the same isotonic solution (control animals). This allowed us to constitute four study groups: (1) the control group (solely perfused with isotonic saline solution), (2) a group perfused with elastase alone, (3) the free DNA alone group and (4) the 
elastase + free DNA group.

In order to visualize the localization of fragmented DNA in the aorta 12 hours after its perfusion, 2 additional rats underwent intra-aortic perfusion with the fragmented DNA solution $(0.25 \mu \mathrm{g} / \mu \mathrm{L})$ labeled with Hoechst $33342(100 \mu \mathrm{M})$.

\section{Ex vivo quantification of calcifications with micro-CT analysis}

Volumetric imaging was performed with the Quantum FX micro-Computed Tomography (micro-CT, PerkinElmer) from the dental faculty of Montrouge (EA 2496 team imaging platform). Ten rats that had undergone intra-aortic perfusion of elastase + free-DNA three weeks previously were anesthetized with pentobarbital. Their aortas were examined sequentially with the Quantum FX micro-CT. The calcium score was established by calculating the ratio between the volume of calcium crystals and the total sample volume using dedicated software (CTAn, Sky Scan) as described by Awan et al. ${ }^{15}$

\section{Ex vivo tissue analyses}

All rats (except the two perfused with the fragmented DNA labeled by the Hoechst solution) were sacrificed 3 weeks after the intra-aortic perfusion. Intraperitoneal anesthesia with pentobarbital was performed. Before death, the vascular system was washed with $40 \mathrm{~mL}$ of isotonic saline using a polyethylene PE50 catheter introduced through the left carotid artery, and $20 \mathrm{~mL}$ of formalin were perfused. Abdominal aortas were harvested and both separated into two parts. The first part was fixed in a $3.7 \%$ paraformaldehyde (PFA) solution and the second part was frozen at $-80^{\circ} \mathrm{C}$.

For the two rats perfused with free DNA associated with the Hoechst 3342 solution, one was sacrificed immediately after the intervention and the other one, after 12 hours. Abdominal aortas were harvested as previously described and frozen in optimal cutting temperature (OCT). 
Harvested aortas were treated as described above (see "Material and Methods" section, "Histological examination of calcifications from human and rat arteries" subsection).

\section{Qualitative evaluation with $\mu$ Fourier Transform Infrared Spectroscopy ( $\mu$ FTIR) and}

\section{Scanning Electron Microscopy $\left(\right.$ SEM) ${ }^{16}$}

Spotlight $400 \mu$ FTIR Imaging system (Perkin Elmer) from the College de France was used to perform a comparative ex vivo qualitative evaluation of rat and human calcifications. The $\mu$ FTIR spectrometer was equipped with a liquid nitrogen-cooled 16-element linear array Mercury Cadmium Telluride (MCT) detector. Aortic slides were disposed on Low-E slides. Neither prior preparation nor staining was necessary. Target zones were pre-identified using Alizarin red staining on serial sections. All $\mu$ FTIR spectra were collected in the mid-infrared from $4000 \mathrm{~cm}^{-1}$ to $650 \mathrm{~cm}^{-1}$ using $16 \mathrm{~cm}^{-1}$ spectral resolution and 64 accumulations for each collection by the array. Absorbance wavelengths of different samples were obtained with the Spectrum software (Perkin Elmer).

A Zeiss SUPRA55-VP SEM was used for observation of calcification microstructure. This field-effect "gun" microscope (FE-SEM) operates at 0.5-30 kV. High-resolution observations were obtained using two secondary electron (SE) detectors: an in-lens SE detector and an Everhart-Thornley SE detector. To maintain the integrity of the samples, measurements were made at low voltage (between 0.5 and $2 \mathrm{kV}$ ) without the usual deposits of carbon on the surface of the sample.

\section{Statistical analyses}

Statistical analyses were performed using the StatView software v5.0 (SAS Institute Inc, Cary, NC). Calculated variables are expressed as median with interquartile range. Results 
were compared using the non-parametric Kruskal-Wallis and Mann-Whitney tests. A $p$ value $<0.05$ was considered significant. 


\section{RESULTS}

\section{Histological examination of calcifications from human and rat arteries, and colocalization with free DNA}

\section{Human arteries}

\section{Spontaneous calcifications in early human atheroma}

Although the human aortas examined were supposed to be healthy, 50\% (3/6) presented macroscopic signs of early atheroma, including fibrous cap atheroma. Histological examination revealed microscopic calcifications. These calcifications were demonstrated by Alizarin red in intimal areas of fibrous cap atheroma. Sometimes, Alizarin red staining extended to the medial layer and potentially also to the macroscopically healthy aorta (Fig. 1A). Alizarin red staining was suppressed by pre-incubation of the section with EDTA (Fig. 1B). DNA immunostaining and Hoechst staining showed extracellular free DNA within calcified areas (Fig. 1D-I). TUNEL assay revealed similar results (data not shown). In contrast to calcifications, this extracellular free DNA background was not suppressed by EDTA (Fig. 1E, H and I). This colocalization of calcifications with DNA was found in all human atherosclerotic specimens (Supplemental Fig. 1).

\section{Characterization of spontaneous calcifications in human aortas}

The different absorption bands of calcium phosphate apatite (CA), amorphous carbonated calcium phosphate (ACCP) and hydroxyapatite crystals (HA) are well known (Fig. 2A). More precisely, the $v_{4} \mathrm{O}-\mathrm{P}-\mathrm{O}$ bending mode corresponds to the doublet at $602-563 \mathrm{~cm}^{-1}$, while the $v_{1}$ and $v_{3}$ P-O stretching vibration modes are measured at $960-962 \mathrm{~cm}^{-1}$ and $1035-1045 \mathrm{~cm}^{-1}$, respectively. Note that the bands at 3570 and $633 \mathrm{~cm}^{-1}$ corresponding to the stretching and vibrational modes of the $\mathrm{OH}^{-}$groups are almost absent for the biological apatites, namely CA, since human apatites are $\mathrm{OH}^{-}$and calcium-deficient. Finally, a key point in the analysis is 
related to the presence of a shoulder around $1065 \mathrm{~cm}^{-1}$ in the $v_{3}$ absorption band, which can be used as a fingerprint for the presence of the ACCP compound. Our analysis revealed that spontaneous calcifications in humans are mainly characterized by the presence of ACCP, and to a lesser extent by CA entities as demonstrated by the shape of the $1074 \mathrm{~cm}^{-1}$ band (Fig. $2 \mathrm{~B}$ and C, corresponding to the serial section of the Supplemental Fig. 1: plaque shoulder in fibro-atheroma). These results were confirmed by SEM, which showed typical calcium phosphate retention in human aortas (Fig. 2D).

\section{Intraluminal calcified buds in human femoral artery}

Intraluminal buds of heavy calcifications were observed in the endarterectomy plaques from the human femoral artery (Fig. 3). These heavily calcified buds did not allow usual sectioning after fixation and paraffin embedding. After treatment of the section by EDTA (rendering the sample to be cut), these buds were histologically characterized by the presence of remnant Alizarin red positive areas (Fig. 3A and B), red blood cells surrounding calcifications (Fig.3C) and free DNA detected by DNA immunostaining (Fig. 3D-F) and Hoechst staining (Fig. 3G-H).

\section{Rat aneurysmal aortas}

As in humans, experimental aneurysms in rats have been reported to contain calcifications in association with free DNA release ${ }^{13}$. Here we used in vivo CT scan to detect calcifications in elastase-induced experimental aneurysms in rats (Supplemental Fig. 2A). These calcifications were also histologically observed in the wall of these aneurysms (Alizarin red, Supplemental Fig. 2B). Hoechst used before EDTA treatment mainly stained cell nuclei but not calcification background (Supplemental Fig. 2C). In contrast, after EDTA treatment, Hoechst no longer 
stained cell nuclei but the extracellular free DNA, which colocalized with Hoechst positive areas even after EDTA treatment of the section (Supplemental Fig. 2D). The presence of

DNA background was confirmed by immunochemistry of extracellular free DNA (Supplemental Fig. 2E) after EDTA.

\section{Rat model of vascular calcifications \\ Intra-aortic penetration of free DNA}

Hoechst prestaining of perfused free fragmented DNA (without Hoechst direct staining of the section) demonstrated an intense intramural localization twelve hours following intra-aortic DNA infusion. The three aortic layers (intima, media and adventitia) displayed positive stained DNA, demonstrating that the free fragmented DNA had largely penetrated into the arterial wall (Fig. 4A-D).

\section{Visualization of calcifications with Alizarin red}

At 3 weeks, no microscopic calcification was seen in sham aortas perfused with saline (not shown). Calcifications appeared in the abdominal aortic segment perfused by free fragmented DNA, as punctiform Alizarin red staining before EDTA treatment and positive Hoechst staining after EDTA treatment (Fig. 4E-H). Among the study groups, nearly no calcifications were detected in the control group and in the elastase group. However, $7 / 9$ (78\%) and 8/9 $(89 \%)$ rat aortas presented microscopic calcifications, in the free-DNA group and the elastase + free-DNA group, respectively.

\section{Ex vivo quantitative evaluation of aortic calcifications}

A total of 36 rat aortas were analyzed ex vivo using micro-CT (9 in the free DNA group, 9 in the elastase + free DNA group, 9 in the elastase group and 9 controls perfused with saline). The calcification sites appeared as white radiopaque areas (Fig.5A and B). 
The calcification scores were statistically different between the groups ( $p=0.003$; KruskalWallis test). The calcification score was significantly higher in the elastase + free DNA group compared to the elastase alone group ( $p=0.005)$, and the control group ( $p=0.002$; Fig. 5C).

\section{Characterization of calcifications induced in rat aortas}

$\mu$ FTIR experiments performed on a set of rat aortas from the elastase + free DNA group demonstrated the presence of CA deposition via the measurements of the absorption band positioned at $1026 \mathrm{~cm}^{-1}$ (Supplemental Fig. 3). In contrast to human arteries, there was less ACCP deposition. 


\section{DISCUSSION}

The etiopathogenesis of microcalcifications in the arterial wall probably varies depending on local and general environment ${ }^{14}$. In particular, two stages have been identified: a first one in which cell-released extracellular microvesicles, exosomes and apoptotic bodies are identified as hot spots of calcium phosphate precipitation ${ }^{15}$, due to the presence of exposed phosphatidyl serine, annexins, $\mathrm{S} 100 \mathrm{~A} 9^{10}$, and the release of inorganic phosphorus or phosphates, and a second one in which vSMCs acquire an osteoblast-like phenotype leading to the development of bone-like tissue within the arterial wall ${ }^{16}$. In this context, prelamin A has been identified as promoting vSMC calcification and senescence by inducing DNA damage ${ }^{17}$. Since calcium phosphate can be cleared by fetuin, a circulating plasma protein able to form complexes with $\mathrm{it}^{18}$, calcium phosphate must be precipitated on a matrix as a necessary step in order to be retained within the soft tissue.

In the present study we identified free DNA as a potential nidus for calcium phosphate precipitation and hydroxyapatite crystallization in the early stages of human atheroma. We colocalized free DNA with sites of calcification development in human aortic fibrous cap atheroma (Fig. 1). A well-formed plexogenic core surrounded by an overlying fibrous cap characterizes fibrous cap atheroma ${ }^{19}$. The plexogenic core is made of a combination of lipids and cellular debris while the fibrous cap consists in vSMC in a collagenous proteoglycan matrix, with varying degrees of infiltration by macrophages and lymphocytes. Initial plaque formation is characterized by the disappearance of vSMCs and DNA release, particularly in the shoulder area. We also identified similar aspects in the shoulder of initial aortic plaques (Supplemental Fig. 1). Since the calcium phosphate precipitation could limit the accessibility of the DNA ligand, we pretreated the sections with EDTA, a chelator of divalent cations, a method that allows the subsequent detection of DNA by an anti-DNA antibody, TUNEL assay or Hoechst staining. Noteworthy, EDTA also chelates ionized iron. 
Observations with a FE-SEM to depict the structural characteristics of abnormal deposits at the nanometer scale have been performed. On the very same samples, their chemical identification at the micrometer scale has been made via $\mu$ FTIR spectroscopy. Previous publications $^{20,21}$ have already underlined the fact that such physicochemical techniques are able to provide more significant information than staining procedures alone (such Alizarin red or Von Kossa technique for example). In our case, we were able to point out the presence of amorphous carbonated calcium phosphate (ACCP), a chemical phase considered as the precursor of calcium phosphate apatite (CA), in combination with CA in human arteries (Fig. 2). Such observations may indicate that, in human arteries, we observed a dynamic phenomenon including the very first steps of the calcification process highlighted by ACCP presence, along with a more advanced phase characterized by CA. In contrast, the rat calcifications appeared to only display isolated CA. This may be related to the characteristics of our experimental model in which a single free DNA perfusion was performed three weeks before sacrifice. An earlier observation of the perfused rat aortic wall may reveal a combination of ACCP and CA. This point remains to be demonstrated in further study.

Macroscopically, calcified intraluminal buds leading to stenosis are more frequent in femoral than in carotid arteries ${ }^{22}$. Therefore we raised the question of the potential role of free DNA in the formation of this specific form of stenosis. Using EDTA-induced incomplete decalcification, we observed that intraluminal calcium phosphate accumulation usually developed on a collagen matrix background and was always associated with micro- or macrohemorrhages. This EDTA-resistant background was enriched by DNA, which can be detected by Hoechst 33342 and an anti-DNA specific antibody. The intraluminal budding of calcification could be related to an initial luminal protrusion of calcium phosphate crystals on which circulating free DNA could bind, causing calcium phosphate to precipitate, forming a vicious circle of DNA/calcium phosphate precipitation ${ }^{23}$. 
The aortic wall of human AAA is highly calcified. We recently published in an experimental model of AAA that repeated injections of weak pathogens increased the aneurysm diameter by increasing the neutrophil content in the intraluminal thrombus ${ }^{24}$, enhancing both the content and release of cell-free DNA and wall calcifications in rat $^{13}$. Thus, here we tested the hypothesis that this increase in calcifications could be linked, at least in part, to the presence of free DNA. We also observed that vascular calcifications in human atherosclerosis were always associated with micro- or macrohemorrhages. In this context, rigid calcifications in the distensible arterial wall introduce a compliance mismatch between the calcification and the soft tissue and failure stress with tears at the interface ${ }^{25-27}$. One of the methodological consequences of this phenomenon is the difficulty in using fluorescent technology for immunostaining, due to the autofluorescence of hemoglobin.

Finally we developed a rat model of intraluminal infusion of free small fragments of DNA alone, or associated with elastase, in order to enhance the radial convection of DNA through the aortic wall. In this model, DNA pre-stained with Hoechst 33342 was easily detectable throughout the wall and the infused segment developed nidi of calcification. These nuclei could be due to a direct ability of free DNA to precipitate calcium, although an indirect effect cannot be completely excluded. In this experimental model, the quantity of calcium precipitate measured by microCT appeared to be grossly associated with the level of radial convection of DNA. The calcium score was significantly higher in the elastase + free DNA group, and it should be recalled that elastin breakdown might play a direct role in calcium phosphate precipitation ${ }^{28}$. Of note, infusion of elastase without DNA failed to create substantial calcifications.

Vascular calcifications have been particularly studied in the setting of end-stage renal disease (ESRD) with dialysis ${ }^{29}$, and in a less manner in diabetes mellitus ${ }^{30}$. The incidence of vascular calcifications is highly increased in these conditions ${ }^{31}$ and is associated with an increased 
cardiovascular risk ${ }^{32}$. Recent works demonstrated that circulating free DNA was increased in these settings ${ }^{33}$ and also associated with cardiovascular morbi-mortality ${ }^{34,35}$. Our study demonstrates that radial convection of free DNA allows it to precipitate with calcium phosphate overload. Therefore, increased levels of free-DNA combined with defective clearance $^{36}$ could be involved in vascular calcifications observed in ESRD and diabetes mellitus patients. Since other mechanisms of vascular calcification have been previously described in these settings, this point remains to be confirmed in specific experimental models.

Taken together, these different observational and experimental results suggest that free DNA, present in the arterial tissue in relation to cell death, could represent one type of molecular platform able to initiate calcium phosphate precipitation and CA crystal formation. This mechanism does not exclude the other well-described biological processes, particularly that involving microvesicle formation by injured cells ${ }^{9,37}$. 


\section{Conflict of interest}

Raphael Coscas received fees from Terumo Inc. and Proteon Therapeutics in the last 36 months. The other authors do not disclose any conflict of interest.

\section{Financial support}

Fondation pour la Recherche Médicale (FRM), Fondation Cœur et Artère.

\section{Author contributions}

Conception and Design: RC, MB, MPJ, DB, JBM; Experimentation: RC, MB, MPJ, JS, JBM. Data interpretation: RC, MPJ, ZM, DB, JBM; Writing the article: RC, MB, JBM; Critical revision of the article: RC, MB, MPJ, LL, ZM, JS, MD, CC, DB, JBM; Statistical Analysis: RC, MPJ; Final Approval: RC, MB, MPJ, LL, ZM, JS, MD, CC, DB, JBM.

\section{Acknowledgments}

The authors thank Mary Pellegrin for providing English editing. 


\section{REFERENCES}

1. Zoccali C, Bolignano D, D'Arrigo G, Dekker FW, Fliser D, et al. and Cardiovascular Medicine Working Group of the European Renal Association-European Dialysis Transplantation A. Validity of Vascular Calcification as a Screening Tool and as a Surrogate End Point in Clinical Research. Hypertension. 2015;66:3-9.

2. Alluri K, Joshi PH, Henry TS, Blumenthal RS, Nasir K et al. Scoring of coronary artery calcium scans: history, assumptions, current limitations, and future directions. Atherosclerosis. 2015;239:109-17.

3. Zeb I, Abbas N, Nasir K and Budoff MJ. Coronary computed tomography as a costeffective test strategy for coronary artery disease assessment - a systematic review. Atherosclerosis. 2014;234:426-35.

4. Otsuka F, Sakakura K, Yahagi K, Joner M and Virmani R. Has our understanding of calcification in human coronary atherosclerosis progressed? Arterioscler Thromb Vasc Biol. 2014;34:724-36.

5. Schoppet M and Shanahan CM. Role for alkaline phosphatase as an inducer of vascular calcification in renal failure? Kidney Int. 2008;73:989-91.

6. Anderson HC. Electron microscopic studies of induced cartilage development and calcification. J Cell Biol. 1967;35:81-101.

7. Bertazzo S, Gentleman E, Cloyd KL, Chester AH, Yacoub MH et al. Nano-analytical electron microscopy reveals fundamental insights into human cardiovascular tissue calcification. Nat Mater. 2013;12:576-83.

8. Kockx MM, De Meyer GR, Muhring J, Jacob W, Bult H et al. Apoptosis and related proteins in different stages of human atherosclerotic plaques. Circulation. 1998;97:2307-15. 
9. Proudfoot D, Skepper JN, Hegyi L, Bennett MR, Shanahan CM et al. Apoptosis regulates human vascular calcification in vitro: evidence for initiation of vascular calcification by apoptotic bodies. Circ Res. 2000;87:1055-62.

10. New SE and Aikawa E. Role of extracellular vesicles in de novo mineralization: an additional novel mechanism of cardiovascular calcification. Arterioscler Thromb Vasc Biol. 2013;33:1753-8.

11. Brown DD and Stern R. Methods of gene isolation. Annu Rev Biochem. 1974;43:667-

93.

12. Xie $\mathrm{Y}$, Chen $\mathrm{Y}$, Sun $\mathrm{M}$ and Ping Q. A mini review of biodegradable calcium phosphate nanoparticles for gene delivery. Curr Pharm Biotechnol. 2013;14:918-25.

13. Delbosc S, Rouer M, Alsac JM, Louedec L, Philippe M, et al. Elastase inhibitor AZD9668 treatment prevented progression of experimental abdominal aortic aneurysms. $J$ Vasc Surg. 2014.

14. Demer LL and Tintut Y. Inflammatory, metabolic, and genetic mechanisms of vascular calcification. Arterioscler Thromb Vasc Biol. 2014;34:715-23.

15. Neven E, De Schutter TM, De Broe ME and D'Haese PC. Cell biological and physicochemical aspects of arterial calcification. Kidney Int. 2011;79:1166-77.

16. Leopold JA. Vascular calcification: Mechanisms of vascular smooth muscle cell calcification. Trends Cardiovasc Med. 2015;25:267-74.

17. Liu Y, Drozdov I, Shroff R, Beltran LE and Shanahan CM. Prelamin A accelerates vascular calcification via activation of the DNA damage response and senescence-associated secretory phenotype in vascular smooth muscle cells. Circ Res. 2013;112:e99-109.

18. Cai MM, Smith ER and Holt SG. The role of fetuin-A in mineral trafficking and deposition. Bonekey Rep. 2015;4:672. 
19. Virmani R, Kolodgie FD, Burke AP, Farb A, Schwartz SM. Lessons from sudden coronary death: a comprehensive morphological classification scheme for atherosclerotic lesions. Arterioscler Thromb Vasc Biol. 2000 May;20(5):1262-75.

20. Bazin D and Daudon M. Some advances in the field of physico-chemical characterization of pathological microcrystals. Ann Biol Clin (Paris). 2015;73:517-534.

21. Dessombz A, Bazin D, Dumas P, Sandt C, Sule-Suso J et al. Shedding light on the chemical diversity of ectopic calcifications in kidney tissues: diagnostic and research aspects. PLoS One. 2011;6:e28007.

22. Herisson F, Heymann MF, Chetiveaux M, Charrier C, Battaglia S, et al. Carotid and femoral atherosclerotic plaques show different morphology. Atherosclerosis. 2011;216:34854.

23. Cerne D and Bajalo JL. Cell-free nucleic acids as a non-invasive route for investigating atherosclerosis. Curr Pharm Des. 2014;20:5004-9.

24. Delbosc S, Alsac JM, Journe C, Louedec L, Castier Y, et al. Porphyromonas gingivalis Participates in Pathogenesis of Human Abdominal Aortic Aneurysm by Neutrophil Activation. Proof of Concept in Rats. PLoS One. 2011;6:e18679.

25. Hoshino T, Chow LA, Hsu JJ, Perlowski AA, Abedin M, et al. Mechanical stress analysis of a rigid inclusion in distensible material: a model of atherosclerotic calcification and plaque vulnerability. Am J Physiol Heart Circ Physiol. 2009;297:H802-10.

26. Kelly-Arnold A, Maldonado N, Laudier D, Aikawa E, Cardoso L et al. Revised microcalcification hypothesis for fibrous cap rupture in human coronary arteries. Proc Natl Acad Sci U S A. 2013;110:10741-6.

27. Terzian Z, Christian Gasser T, Blackwell F, Hyafil F, Louedec L et al. Peri-strut micro-hemorrhages: a possible cause of in-stent neoatherosclerosis? Cardiovasc Pathol. 2016; in press. 
28. Aikawa E, Aikawa M, Libby P, Figueiredo JL, Rusanescu G, et al. Arterial and aortic valve calcification abolished by elastolytic cathepsin $\mathrm{S}$ deficiency in chronic renal disease. Circulation. 2009;119:1785-94.

29. Shanahan CM. Mechanisms of vascular calcification in CKD-evidence for premature ageing? Nat Rev Nephrol. 2013;9:661-70.

30. Lanzer P, Boehm M, Sorribas V, Thiriet M, Janzen J et al. Medial vascular calcification revisited: review and perspectives. Eur Heart J. 2014;35:1515-25.

31. Butt AN and Swaminathan R. Overview of circulating nucleic acids in plasma/serum. Ann N Y Acad Sci. 2008;1137:236-42.

32. Virmani R, Joner $M$ and Sakakura K. Recent highlights of ATVB: calcification. Arterioscler Thromb Vasc Biol. 2014;34:1329-32.

33. Korabecna M, Pazourkova E, Horinek A, Rocinova K and Tesar V. Cell-free nucleic acids as biomarkers in dialyzed patients. $J$ Nephrol. 2013;26:1001-8.

34. Tovbin D, Novack V, Wiessman MP, Abd Elkadir A, Zlotnik M et al. Circulating cellfree DNA in hemodialysis patients predicts mortality. Nephrol Dial Transplant. 2012;27:3929-35.

35. Liu J, Cai X, Xie L, Tang Y, Cheng J et al. Circulating Cell Free Mitochondrial DNA is a Biomarker in the Development of Coronary Heart Disease in the Patients with Type 2 Diabetes. Clin Lab. 2015;61:661-7.

36. Korabecna M, Opatrna S, Wirth J, Rulcova K, Eiselt J et al. Cell-free plasma DNA during peritoneal dialysis and hemodialysis and in patients with chronic kidney disease. Ann N Y Acad Sci. 2008;1137:296-301.

37. Kapustin AN, Chatrou ML, Drozdov I, Zheng Y, Davidson SM et al. Vascular smooth muscle cell calcification is mediated by regulated exosome secretion. Circ Res. 2015;116:1312-23. 


\section{FIGURE LEGENDS}

Fig. 1. Colocalization of free DNA and calcifications in a human aortic fibrous cap atheroma (x20).

EDTA treatment is used to remove calcium crystals. Calcification detection by Alizarin red before (A) and after (B) EDTA treatment of the section. Macroscopic view is shown in C: the yellow lipid core is luminally covered by a white fibro-cellular cap. Corresponding extracellular DNA detected by immunostaining before (D) and after (E) EDTA treatment of the section (DNA in brown). Negative control is shown in F. Hoechst staining is initially negative $(\mathrm{G})$ but EDTA treatment reveals a free DNA background $(\mathrm{H}, \mathrm{I})$ in the calcified area.

Fig. 2. Characterization of calcium phosphate crystals in early human plaques.

(A) Reference infrared spectra of different calcium phosphate compounds: micrometer size crystals of hydroxyapatite (HA; red), nanometer scale crystal of calcium phosphate apatite (CA; blue), and amorphous carbonated calcium phosphate (ACCP; black).

(B) Infrared cartography and (C) spectra of ACCP (blue) and CA (red) in the shoulder of a human atherosclerotic plaque (Alizarin red).

(D) Visualization of calcium phosphate crystals by Scanning Electron Microscopy

Fig. 3. Colocalization of free DNA with calcification in intraluminal buds of a human femoral artery endarterectomy after treatment of sections by EDTA.

Alzarin red staining (A, B) confirms the presence of calcification (in orange), even after EDTA treatment. These calcifications are associated with the presence of red blood cells (RBC) after Diaminobenzidine (DAB) coloration (C). Besides some nuclei, DNA immunostaining confirms the association of free DNA with hydroxyapatite crystals (D, E, F). 
Hoechst staining confirms the free DNA background in areas of hydroxyapatite crystals $(\mathrm{G}$,

H). (I) Macroscopic aspect of corresponding intraluminal buds in a human femoral artery showing the presence of blood associated with calcified lesions.

Fig. 4: Transmural convection of luminally-infused free DNA across the arterial wall. Hoechst staining reveals punctiform presence of infused free fragmented DNA (A) in the 3 layers of the arterial wall (intima, media, adventitia; B, C, D) 12 hours after infusion. The perfused free DNA was prestained by Hoechst whereas the section was not Hoechst-treated. Therefore, the Hoechst positivities only correspond to perfused DNA.

Twenty-one days later, Alizarin red staining shows the presence of punctate nuclei of calcification within the media (E). After calcification removal by EDTA (F), Hoechst staining, which was initially negative $(\mathrm{G})$, reveals the free DNA background $(\mathrm{H})$. The crystal structure is recognizable on this high magnification inset $(\mathrm{X} 40) .(*)$ indicates the suture line on the serial sections.

Fig. 5: Quantification of calcifications in rat aortas infused by free fragmented DNA using microCTscan.

(A) View of a control aorta perfused by saline. (B) View of an aorta perfused by free DNA; calcifications in white. (C) Histogram of quantitative calcification scores (calcified volume /total volume of tissue $\mathrm{X} 10^{-5}$, *** means $p<0.05$ between the groups)

\section{Supplementary Material}




\section{ACCEPTED MANUSCRIPT}

Figure 1: Colocalization of free DNA and Alizarin red positive area in the shoulder of a lipid core from fibrous cap atheroma (x20).

Free DNA is stained using Hoechst (A) without EDTA treatment. Calcification areas are stained using Alizarin red in the corresponding shoulder area (B).

\section{Figure 2: Calcifications of experimentally induced AAA in rat abdominal aorta.}

(A) In vivo visualization of circumferential calcifications (white arrows) by CTscan in an experimental model of aneurysmal abdominal aorta in rats.

(B) Nanozoomer reconstitution of the aneurysmal artery with Alizarin red staining of the dilated aortic wall. Below: enlarged view (X20) of the area of the calcification nucleus.

(C) Corresponding area stained by Hoechst before treatment of the section by EDTA.

(D) Corresponding area stained by Hoechst after treatment of the section by EDTA demonstrating the presence of tissue-free DNA associated with a calcification nucleus.

(E) Immunohistochemistry of free DNA (DAB, brown) in the corresponding area.

Figure 3: Characterization of calcium phosphate crystals in rat aortas infused by elastase and fragmented free DNA.

(A) Experimentally induced calcification nuclei (Alizarin red, red for calcifications).

(B) Infrared cartography and (C) infrared spectra identifying calcium phosphate apatite (CA) alone. In the cartography, colors indicate CA intensity based on the $1026 \mathrm{~cm}-1$ position (green line).

(D) Scanning Electron Microscopy showing calcium phosphate deposition. 

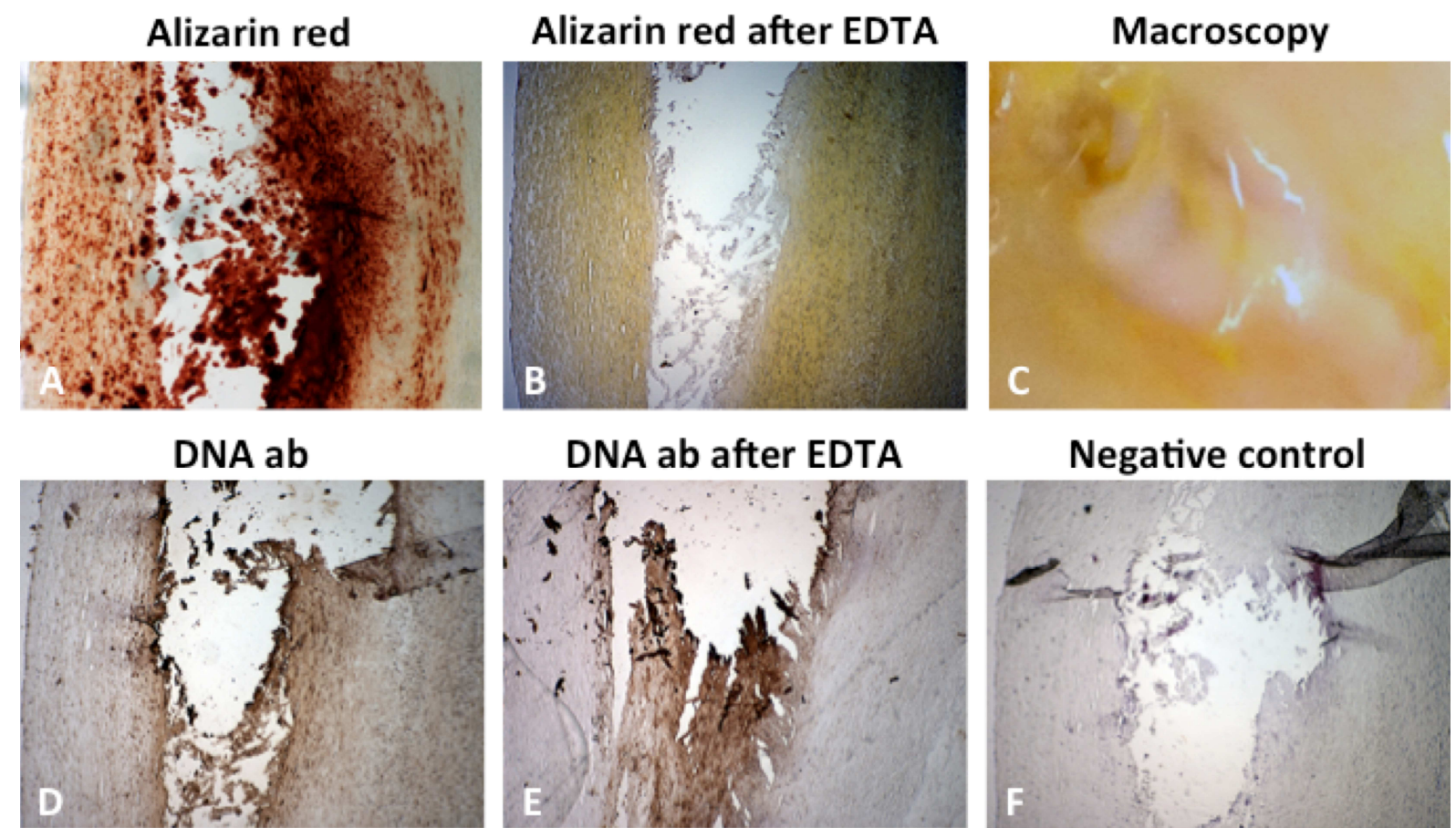

Negative control

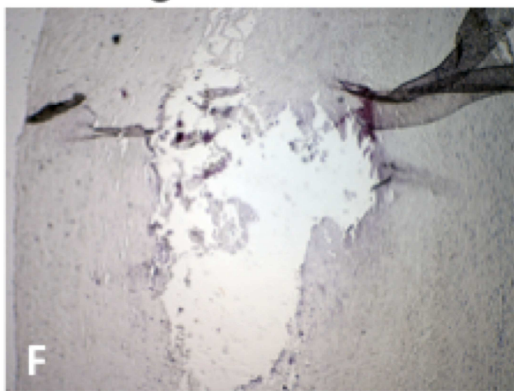

Hoechst
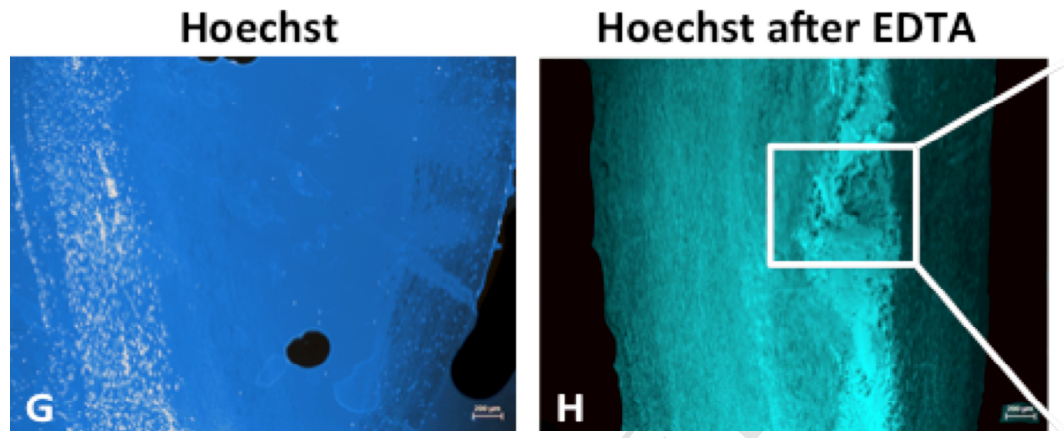

Hoechst after EDTA X 20

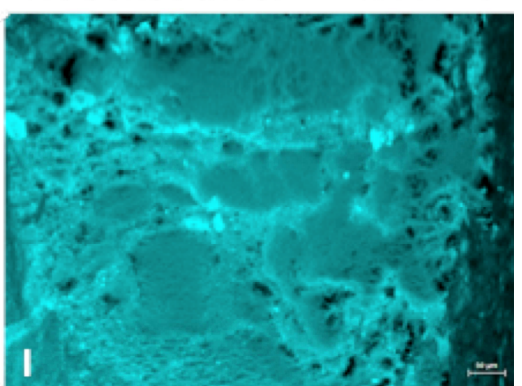




\section{A}

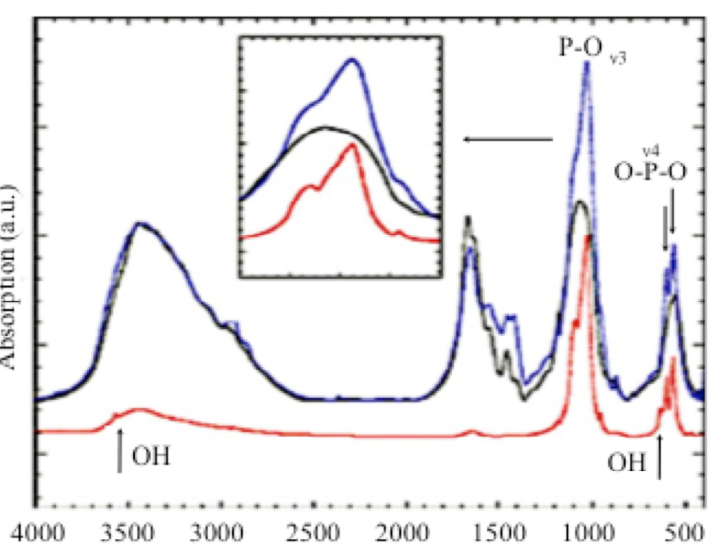
$\mathrm{v}\left(\mathrm{cm}^{-1}\right)$

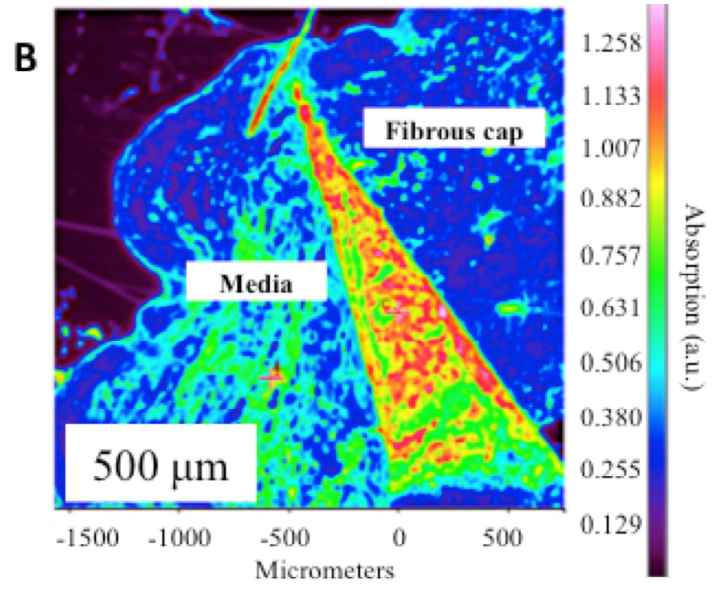

C
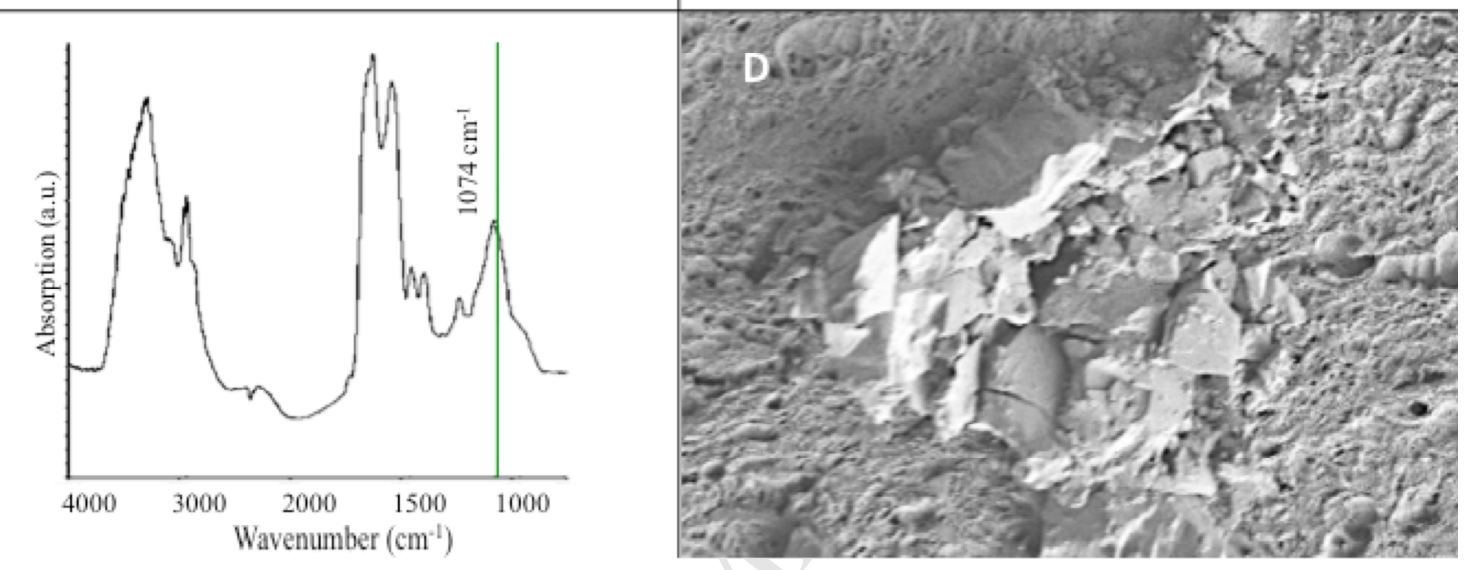

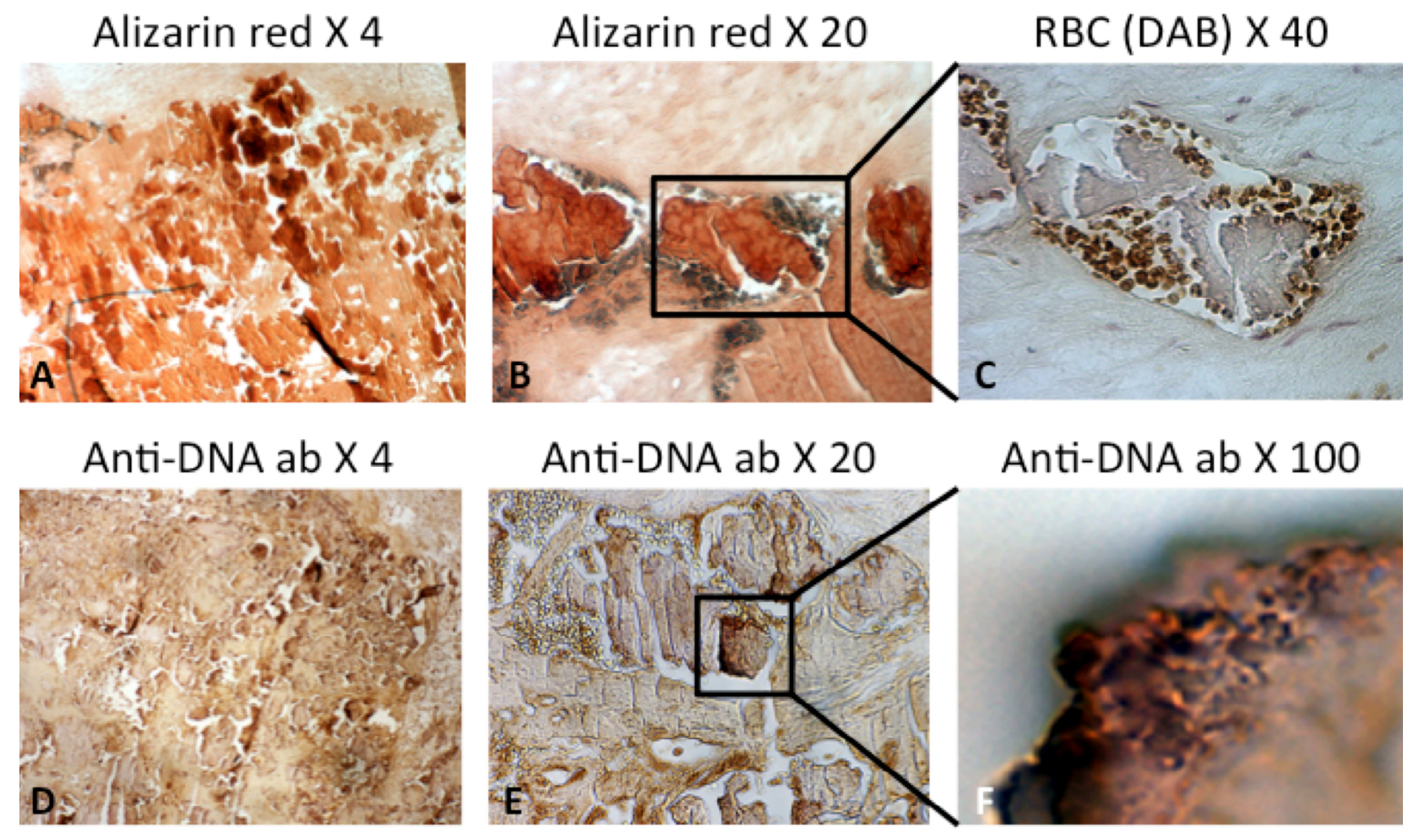

Anti-DNA ab X 100

Hoechst X 4

Hoechst X 100
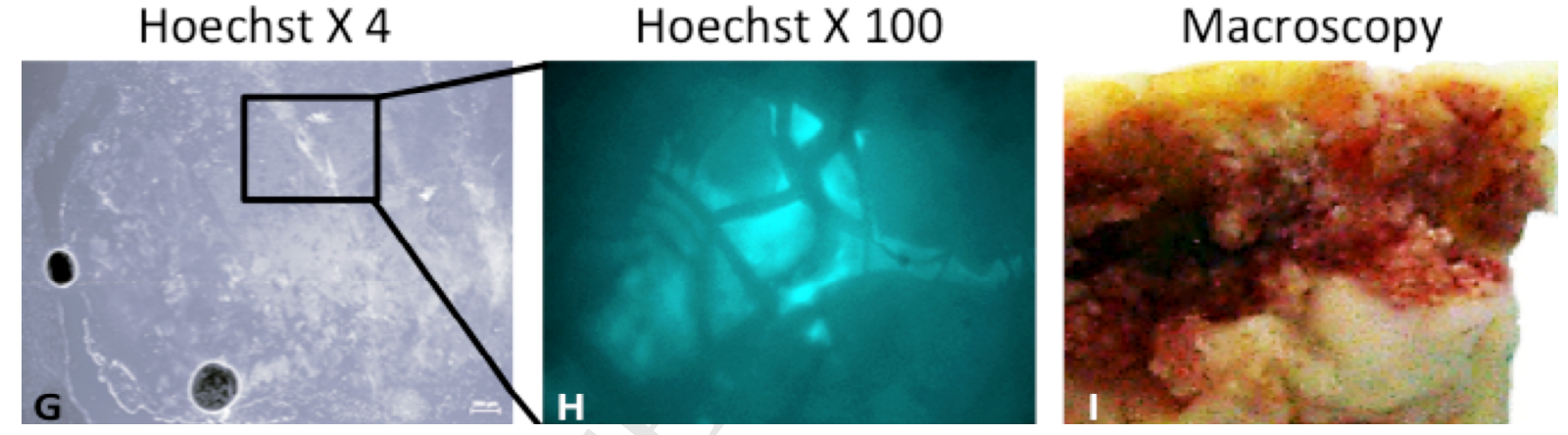


\section{ACCEPTED MANUSCRIPT}
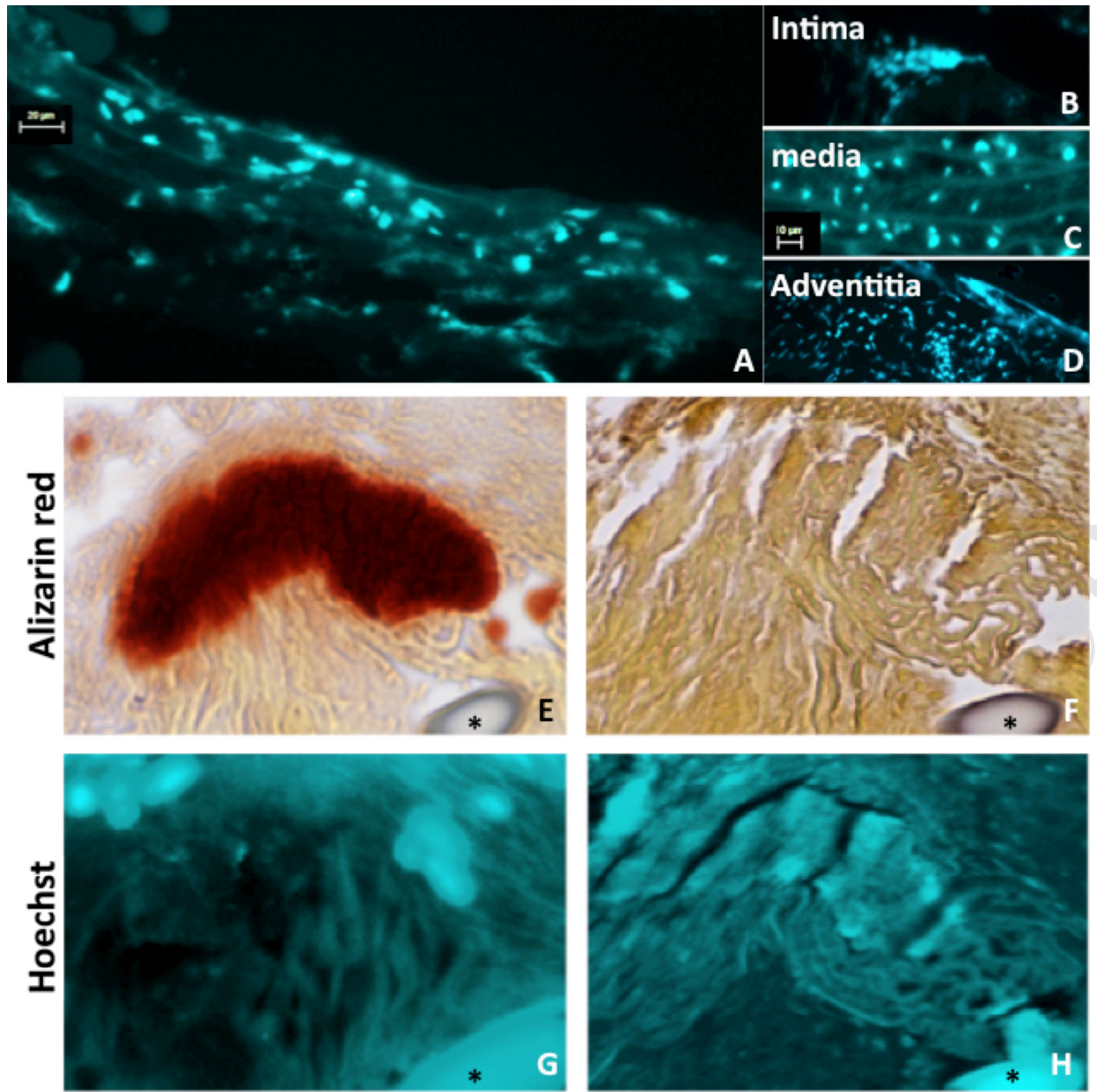

EDTA -

EDTA + 

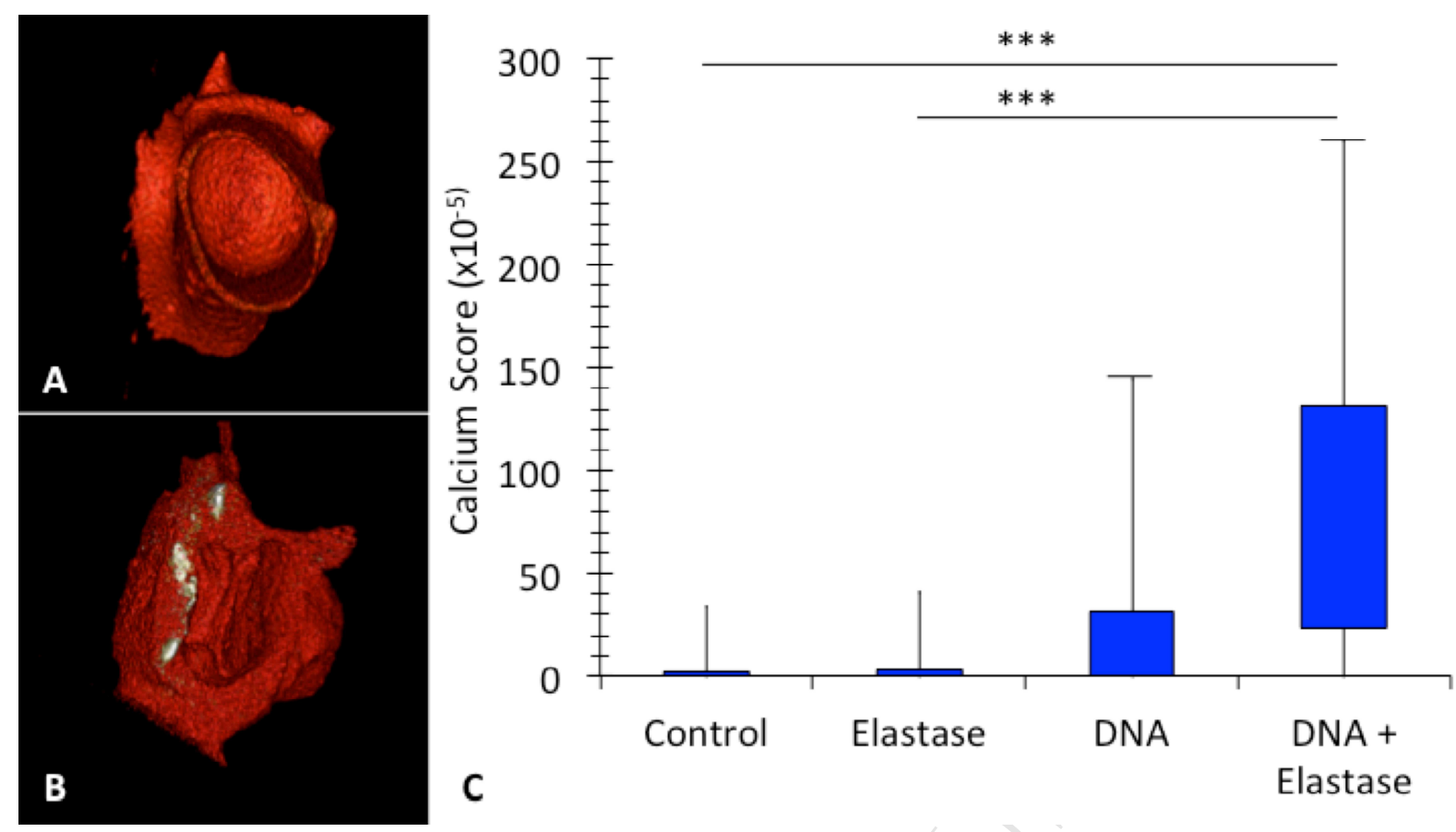


\section{Highlights:}

- Free DNA colocalizes with calcifications in human and rat arteries

- EDTA calcium chelation allowed to identify free DNA as background of calcification

- A calcification model based on intra-aortic free DNA infusion is presented

- Free DNA may serve as an anionic platform precipitating calcium phosphate 